\title{
A HISTORIA MAGISTRA VITAE NO BRASIL NO SÉCULO XIX: DARIO VELLOZO E OS ENSINAMENTOS DE HISTORIA
}

\author{
Ernando Brito Gonçalves Junior* \\ Vanessa Elisabete Raue Rodrigues**
}

\section{RESUMO}

O presente artigo discute a maneira que Dario Vellozo utilizou a história como uma estratégia de intervenção social. Para darmos conta desse pleito, utilizamos como fonte algumas obras escritas, observando que a história deveria ensinar o presente sobre os erros e acertos do passado para que não ocorressem os mesmos enganos no futuro, nos mesmos moldes da historia magistra vitae, transformando o conhecimento histórico em uma importante faceta do conhecimento cultural para Vellozo.

Palavras-chave: história, conhecimento histórico, história intelectual.

*Universidade Estadual do Centro Oeste (Unicentro), Guarapuava/PR, Brasil.

${ }^{* *}$ Universidade Estadual do Centro Oeste (Unicentro), Guarapuava/PR, Brasil. 


\section{LA HISTORIA MAGISTRATIVA DE VITAE EN BRASIL EN EL SIGLO XIX: DARIO VELLOZO Y LAS ENSEÑANZAS DE LA HISTORIA}

\section{RESUMEN}

Este artículo analiza la forma en que Dario Vellozo utilizó la historia como estrategia para la intervención social. Para dar cuenta de esta afirmación, utilizamos como fuente algunos trabajos escritos, señalando que la historia debe enseñar al presente sobre errores y éxitos pasados para que no ocurran los mismos errores en el futuro, de la misma manera que la historia magistra vitae, convirtiendo el conocimiento histórico en una faceta importante del conocimiento cultural para Dario Vellozo.

Palabras clave: historia, conocimiento histórico, historia intellectual.

\section{THE MAGISTRATIVE VITAE HISTORY IN BRAZIL IN THE XIX CENTURY: DARIO VELLOZO AND THE TEACHINGS OF HISTORY}

\section{ABSTRACT}

This article discusses the way Dario Vellozo used history as a strategy for social intervention. To account for this claim, we use as a source some works written, noting that history should teach the present about past mistakes and successes so that the same mistakes in the future would not occur, in the same way as the historia magistra vitae, turning historical knowledge into an important facet of cultural knowledge to Dario Vellozo.

Keywords: history, historical knowledge, intellectual history.

\section{L'HISTOIRE MAGNIFIQUE DE VITAE AU BRÉSIL AU XIX SIÈCLE: DARIO VELLOZO ET L'ENSEIGNEMENT DE L'HISTOIRE}

\section{RÉSUMÉ}

Cet article traite de la manière dont Dario Vellozo utilisé l'histoire comme stratégie d'intervention sociale. Pour rendre compte de cette affirmation, nous utilisons comme source des travaux écrits, notant que l'histoire devrait enseigner au présent les erreurs et les succès du passé, afin que les mêmes erreurs ne se reproduisent plus, à l'instar du historia magistra vitae, transformant la connaissance historique en une facette importante de la connaissance culturelle pour Vellozo.

Mots-clés: histoire, connaissances historiques, histoire intellectuelle. 


\section{AS CONSIDERAÇÕES INICIAIS...}

A história de Dario Velloso, intelectual, escritor e professor paranaense, mistura-se à história do Estado do Paraná e a construção de Curitiba, local forjado pela exclusão, mediante o discurso da construção da cidade Sorriso, com finalidade modernizadora.

Entre os anos 1885 e 1937, Velozzo ocupou-se de espaços da mídia escrita e da educação para divulgar suas ideias, levantando a bandeira da escola Moderna num propósito de transformação da educação paranaense. Seu amadurecimento intelectual fez pensar a sociedade da época e, engajado num movimento em defesa da liberdade de pensamento, reverberou na imprensa paranaense.

Tal condição o fez interagir com o contexto social, procurando, pelo conhecimento histórico, a sua função prática, tornando-a peça-chave na elaboração de estratégias na intervenção social.

Dessa forma, podemos afirmar que Vellozo foi modificador do pensamento do seu tempo ao apontar que o conhecimento histórico ensina sobre o passado, com possíveis e necessárias reflexões sobre o futuro, fato que torna as ações do presente mais bem elaboradas. Esse entendimento é próximo da compreensão do orador e pensador romano, Marco Túlio Cícero, na Antiguidade Clássica, a chamada historia magrista vitae, a qual discutiremos ao longo do proposto.

\section{O JOVEM INTELECTUAL...}

Dario Persiano de Castro Vellozo nasceu no dia 26 de novembro de 1869, em Retiro Saudoso, bairro de São Cristóvão, no Rio de Janeiro. Seus pais foram Ciro Persiano de Almeida Vellozo e Zulmira Mariana de Castro Vellozo. Sua infância foi “[...] confortável, rica e formosa, na ventura de um lar abastado, 
de cuja superior organização lhe vieram, por certo as linhas aristocráticas de seu temperamento fidalgo" (SILVEIRA, 1921, p. 12). Aprendeu suas primeiras letras com sua mãe e muito de sua educação e de seu contato com livros veio do seio familiar. D. Zulmira morreu quando Vellozo tinha apenas dez anos, em 1879, fazendo com que seu pai se tornasse sua principal referência familiar e o "grande amigo que sempre foi" (VELLOZO, 1969c, p. 310). Entre os anos de 1880 e 1883, iniciou seus estudos secundários no Liceu de São Cristóvão e, concomitantemente, tentou seguir a carreira militar de seu pai, matriculando-se na Escola Naval. Fez três tentativas para ser aceito, em 1882, 1883 e 1884, mas foi reprovado em todas (PILOTTO, 1969, p. 19).

Percebemos que Vellozo teve uma infância relativamente confortável, sem muitas dificuldades financeiras, fato este que possibilitou o começo de seus estudos logo cedo. Isso o propiciou que pleiteasse uma vaga no corpo militar, do qual seu pai fazia parte, apesar de ter sido reprovado, como informamos acima. Provavelmente, a sua boa relação com o pai tenha sido decisiva para que Vellozo tentasse seguir a mesma profissão, e podemos pensar ainda que algumas das ideias de civismo e patriotismo defendidas pelo intelectual ao longo de sua vida possuem ligações com a sua relação familiar.

Sua inserção no mundo do trabalho também começou cedo. Em 1884, exerceu função de aprendiz de encadernador na Oficina Lombaerts e Cia. No ano de 1885 , foi aprendiz de compositor tipográfico na Oficina de Moreira, Maximino e Cia (NEGRÃO, 1929). É interessante notar que os primeiros trabalhos de Vellozo estão relacionados ao mundo da editoração, e essa familiaridade possibilitou, mais tarde, que ele atuasse em várias revistas e jornais com essa função.

Em agosto de 1885, Vellozo chega às terras paranaenses com seu pai e seu irmão, Tito Vellozo. Nesse mesmo ano, trabalha como compositor tipográfico no Dezenove de Dezembro, o primeiro jornal instalado na nova província do Paraná (VIEIRA, 2007). Percebemos que o pai, Ciro Vellozo, teve um papel importante na inserção de Dario no cenário intelectual de Curitiba 
devido às suas atuações no Estado. Além de Ciro ter sido prefeito de Curitiba (1895-1896), ele também foi presidente do Club Curitibano entre os anos de 1889 e 1891. Sua principal contribuição nesse clube foi a fundação da Revista do Club Curitibano, em 1890, na qual divulgava textos de vários autores da cidade. Foi nas páginas dessa revista que Dario Vellozo publicou seus primeiros escritos.

Além do prestígio do pai de Dario Vellozo no cenário curitibano, outro fator importante para a sociabilização de Vellozo com os jovens intelectuais desse contexto foi a respeitável biblioteca que Ciro Vellozo possuía. A casa da Família Vellozo tornou-se um centro de encontro dos jovens curitibanos, um local onde eles podiam discutir, escrever e ler vários textos, pois, devido ao interesse de Ciro Vellozo pelo estudo, havia lá um volume considerável de livros. Isso causou uma grande admiração e interesse por parte dos seus colegas de estudos. A esse respeito Silveira Netto conta que:

Um dia abordei à sua residência, bati palmas cerimoniosamente e, aberta, apontaram-me íngreme escada por onde se ia dar a um vasto Karoim subterrâneo atopetado de estantes repletas de livros. [...] Passávamos horas inteiras manuseando livros, discutindo questões de músculos e de inteligência, estabelecendo planos de trabalho e sonhando (NETTO, 1894, p. 7).

Essas reuniões eram uma extensão dos encontros desses jovens, que também ocorriam nas escolas. Entre os anos de 1886 e 1889, Vellozo estudou no Partenon Paranaense e no Ginásio Paranaense (PILOTTO, 1969). Foi nesses estabelecimentos de ensino que Vellozo conheceu vários dos jovens que fizeram parte do cenário intelectual curitibano do início do século XX, como Silveira Netto, Nestor Victor, Júlio Pernetta, Ermelino de Leão, entre outros.

É possível perceber, assim, alguns fatores que construíram as relações de amizades criadas por Vellozo e o inseriram no mundo das letras. O papel de seu pai em Curitiba - na criação de revistas, na presidência de clube literário e até na política - agregou um maior respeito à figura do jovem Vellozo. $\mathrm{O}$ fato de 
a sua família possuir um grande volume de livros também pode ser considerado importante, pois facilitou a aproximação de Dario com seus colegas, o que já vinha acontecendo por meio das aulas no Partenon Paranaense e no Ginásio.

\section{AS PRODUÇÕES INICIAM...}

A partir das reuniões em sua casa e da convivência com outros jovens amantes das letras, Vellozo publicou, junto com um grupo de amigos, um periódico chamado $O$ Mosqueteiro, em 1884. No ano de 1889 , Vellozo publica sua primeira obra, Primeiros Ensaios, livro que possui três contos.

Os acontecimentos no cenário brasileiro desse período também faziam parte da pauta de discussões de Vellozo. Na Revista do Club Curitibano, ele publicou alguns textos analisando a abolição, temática sobre a qual também proferiu discursos no salão do mesmo clube, sempre se mostrando a favor da causa. A ideia de instauração de uma República era outro discurso forte no período. Segundo Vellozo, "a República surgira como uma animadora promessa à mocidade brasileira" (VELLOZO, 1969b, p. 110). Ele foi um ferrenho defensor desse sistema político por toda sua vida.

Vale lembrar que o final do século XIX e início do século XX foi marcado por intensas transformações no cenário nacional, tanto em correntes de pensamento que estavam em voga no período, quanto em estruturas físicas de diversas cidades do país. Seguindo o exemplo dos grandes centros brasileiros, como São Paulo e Rio de Janeiro, o Estado do Paraná também respirou esses ares de mudanças. De acordo com Etelvina de Castro Trindade e Maria Luiza Andreazza, “[...] qualquer pessoa que chegasse às cidades paranaenses no período da Primeira República encontraria, em maior ou menor grau, alguns signos da então moderna tecnologia: telégrafo, telefone ou luz elétrica; depois, automóveis e bondes" (TRINDADE; ANDREAZZA, 2001, p. 66). 
Ao mesmo tempo em que se fazia uma intensa propaganda de ideias defensoras da consolidação de uma sociedade dita moderna pautada nos signos do progresso do século XIX, os poderes públicos promoviam algumas modificações no cenário urbano daquele momento, como alargamento das avenidas, higienização do centro da cidade e ampliações da iluminação pública, do sistema de esgoto e de distribuição de água. Essas ações faziam parte da ideia de modernizar a cidade aos moldes da Belle Époque (TRINDADE; ANDREAZZA, 2001). Essas e outras transformações, não apenas em aspectos físicos da cidade, mas também em aspectos culturais - como novas ideias educacionais, movimentos sociais e várias correntes de pensamentos filosóficos - eram retratadas em jornais e revistas, transformando esses órgãos em importantes veículos de divulgação.

A maioria dessas mudanças foi financiada por uma elite econômica em desenvolvimento, ligada à exploração do mate e da madeira, ou ainda preocupada em criar novas indústrias. Vale lembrar que esses grupos formados por brasileiros detiveram a força política no Paraná republicano no final do século XIX e início do século XX (CORRÊA, 2006). Em contrapartida a esses grupos que detinham o poder político e econômico, ideias anarquistas e socialistas começaram a circular no Paraná, trazidas por imigrantes pobres e sem representatividade política no período (VALENTE, 1992).

Neste sentido, Amélia Siegel Corrêa aponta, em sua dissertação acerca da imprensa e política no Paraná, que as ideias de modernização

[...] refletiam-se no desenvolvimento material da cidade, cada vez mais urbanizada, com alterações arquitetônicas, difusão da luz elétrica, bondes, calçadas, telégrafo. Obras como a Estrada da Graciosa, concluída em 1873, e a ferrovia, entregue em 1885, trouxeram para a capital vários engenheiros (CORRÊA, 2006, p. 31).

Contudo, é digno de nota que, apesar de serem uma tentativa de modernizar Curitiba, essas mudanças não ocorriam em todo o território da 
cidade. O Centro era o principal foco de transformações, e a periferia da cidade ainda continuava em um ritmo provinciano, que pouco tinha contato com os ares de modernização. Assim, Curitiba enfrentava um paradoxo: ao mesmo tempo em que alguns locais passavam por profundas mudanças para tentar se aproximar dos grandes centros, outros ainda permaneciam à margem dessas transformações. Esse paradoxo não era exclusividade de Curitiba, pois o mesmo acontecia em nível estadual e nacional. O Brasil se desenvolvia em velocidades diferentes.

Vellozo assistiu a essas mudanças e atuou, em alguma medida, para que outras acontecessem, principalmente nas formas de pensar e de agir da sociedade. A Curitiba desse período teve um cenário intelectual muito rico, com uma grande quantidade de livros, revistas e jornais que foram publicados nesse contexto. Houve também uma grande diversidade de opiniões, tendências e ramificações políticas, literárias e filosóficas, como, por exemplo, ideias anarquistas, disputa de ideais entre anticlericais e católicos, a presença da literatura simbolista , ocultista e esotérica, casas maçônicas e centros pitagóricos.

Essas correntes de pensamento tiveram um importante papel no cenário político e social da cidade, fazendo com que vários intelectuais divulgassem propostas e tentassem cooptar um número maior de adeptos para seus grupos e agremiações. Assim, as várias transformações em diversos âmbitos sociais foram algumas das tintas que deram cores ao cenário curitibano do final do século XIX e início do século XX, e podemos perceber que Dario Vellozo ajudou a pintar esse quadro, pelo menos no que diz respeito às ideias do período.

Neste sentido, no ano de 1895 Vellozo participa da fundação da revista O Cenáculo, veículo de comunicação que teve um grande impacto na imprensa paranaense, como será discutido no decorrer do texto. Nessa época, ele estava adentrando mais profundamente em seus estudos ocultistas, além de começar a ter mais contato com as ideias maçônicas. Logo, são criadas revistas voltadas 
aos ideais maçons e ocultistas, sempre com a participação de Vellozo, em menor ou maior grau. Além de revistas, o intelectual escreveu alguns livros doutrinários para divulgar suas ideias. Assim, em seu livro Templo Maçônico, ele comenta:

[...] a oportunidade se me deparou de meditar os símbolos da Maçonaria. Vibrou-me intenso entusiasmo, e comecei de tributar todo um culto à gloriosa mensageira da VERDADE e do BEM que, através dos séculos, vem abrigando largos sulcos de caridade e justiça. Segue-a importante cortejo de adeptos que proclamam; estorcem-se à sua passagem os inimigos da Luz. [...] Este livro - Subsídios Maçônicos é apenas testemunho de meus aplausos à GRANDE INSTITUIÇÃO. Escrito com amor e sinceridade, indaga das origens da FrancoMaçonaria, apresentando-as de acordo com trabalhos históricofilosóficos da moderna escola esotérica (VELLOZO, 1975, p. 21-22).

Vellozo acreditava que a maçonaria poderia levar as palavras da verdade, da ciência, da justiça e do bem para todas as pessoas, por isso, ele assumiu o papel de educador maçom, tentando divulgar as ideias da instituição e cooptar adeptos para seus pensamentos.

A partir de reuniões em congressos maçons, Vellozo entra em contato com Girgois, Supremo Delegado da América do Sul, do Groupe Independance de Études Esotèriques, de Paris, fundado e dirigido por Papus, e, nesse mesmo período, ingressa na Association Alchimique de France (BEGA, 2001). Ainda no ano de 1899, com base nas ligações expostas acima, Vellozo fundou o Centro Esotérico Luz Invisível, com autorização do Groupe Independance de Études Esotèriques, tendo a revista Esphynge como o principal veículo de divulgação de suas ideias. Devido a essas ligações e a seu estudo, em 1905, Vellozo recebe o diploma de mestre em hermetismo pela Escola Superior de Ciências Herméticas, de Paris, dirigida por Papus. Essas ligações de Vellozo nos mostram um pouco da fonte de pensamento esotérico e ocultista com a qual ele dialogava.

No ano de 1899, Vellozo consegue o cargo que, sem dúvida, lhe trouxe mais prestígio no cenário paranaense. Ele foi efetivado como professor do 
Ginásio Paranaense e da Escola Normal. Foi ocupando esses espaços que o autor conseguiu divulgar suas ideias, ser reconhecido como um importante professor e pensador, agregando mais valor à sua imagem no período.

Como professor, Vellozo começou a demonstrar mais interesse pela temática educacional, e transformou o assunto em um de seus principais temas de discussão. Ele levantou a bandeira da Escola Moderna, como sendo o projeto capaz de transformar e melhorar a educação. Podemos identificar uma maior produção sobre a temática educacional nas obras de Vellozo entre os anos de 1902 e 1910, seja com a publicação de livros ou em artigos de revistas. Em 1902, publica o livro Lições de História; em 1903, o texto Escola Moderna; em 1904, é a vez de Da instrução Pública; e, no ano seguinte, de No sólio do Amanhã. Em 1905, Vellozo escreve o texto Voltaire, no qual tece várias críticas à Igreja Católica, e o utiliza para confirmar e reforçar suas acusações. Em 1906, começa a ser publicada a revista $A$ Escola, fundada pelo Grêmio dos professores do Ginásio Paranaense e da Escola Normal. Nessa revista, Vellozo expôs vários de seus projetos pedagógicos, sendo o principal local de divulgação de suas ideias relacionadas à educação. Em 1907, ele passa a dirigir a revista, da qual se afastaria em 1910. Ainda no ano de 1907, publica o livro Compêndio de Pedagogia.

\section{O MARCO DA INTERVENÇÃO SOCIAL...}

Com seu amadurecimento intelectual, Vellozo buscou alternativas para pensar a sociedade. Em 1909, fundou o Instituto Neo-Pitagórico (INP), que tinha como foco: "[...] propor uma nova ordem ética, que não fosse baseada num simples comportamentalismo, mas fundamentada na fusão das tradições Orientais e Ocidentais" (ANDRADE, 2002, p. 136). Nesse sentido, o INP tentou difundir a liberdade de pensamento, mostrar outras maneiras de pensar a vida com base na natureza e no cosmos, pois, segundo Tasso da Silveira: 
[...] algo mais havia que fazia a tortura moral do Mestre: era a desorientação da Sociedade moderna, na qual se reflete o estado caótico do espírito da época. Tudo na sociedade moderna vai errado: o modo de pensar, de agir, de viver, enfim, tudo se ressente da necessidade de uma reforma completa. Em ponto de vista religioso, os sectarismos já não podem satisfazer, dando o antagonismo absoluto entre a doutrina simples e pura dos Doutrinadores e o luxo espantoso e fátuo dos cleros. [...] O materialismo, (sensualismo, Fenomenismo, etc.) não pode subsistir. [...] Algo que se deve fazer em prol do movimento de reorbitação. [...] O desejo de pôr em prática a Moral Pitagórica, humana, baseada na lógica e no racionalismo, sem superstições e sem autoritarismo. [...] O INP procurará naturalmente despertar nas almas a satisfação íntima que vem, não do gozo abjeto, mas das suaves afetuosidades, do carinho supremo, da fraternidade sublime, levando as Sêre, pelo estudo do Cosmos, a convicção de que tudo em Natureza é uno e dependente, tudo coparticipa da Harmonia Universal (SILVEIRA, 1921, p. 36-37).

Vellozo entendia que o INP fazia parte do projeto da Escola Moderna, pois cada instituição teria um foco: enquanto o INP formaria o "espírito", estudando o Cosmos e a natureza, a Escola Moderna formaria o cidadão para a sociedade, com base no trabalho, nas ciências e no ensino cívico. Assim, "a ideia do INP emergiu em meu espírito em 1909, como complemento à de nossa ESCOLA MODERNA” (VELLOZO, 1969a, p. 86).

Com o intuito de colocar em prática suas ideias sobre a Escola Moderna, Vellozo criou, em 1914, na cidade de Rio Negro/PR, a Escola Brazil-Cívico. Esta escola possuía como base os pressupostos teóricos da Escola Moderna que tanto Vellozo defendeu, possuindo uma educação que incluía esportes, agricultura, humanidades e iniciação científica (ANDRADE, 2002).

Na Escola Brazil-Cívico, o binômio teoria/prática era uma constante. Cada ano era dividido em aulas teóricas e aulas práticas. As aulas teóricas versavam sobre diversos temas, como português, francês, geografia, história, desenho, química, botânica, entre outros. E as aulas práticas contemplavam o trabalho, esporte e artes, por exemplo: jardinagem, artes e ofícios, natação, horticultura, agricultura, esgrima, e assim por diante (VELLOZO, 1969c). Aqui, percebemos a união de disciplinas ligadas a um conhecimento humanístico 
(história, francês, desenho, entre outros) com disciplinas ligadas aos conhecimentos científicos (química e botânica), mostrando-nos um pouco da preocupação do intelectual em possibilitar uma educação mais ampla, interligando diferentes áreas do conhecimento.

Apesar de todos os esforços de Vellozo e de outros participantes do projeto da Escola Brazil-Cívico, ela foi interrompida em 29 de agosto de 1914, pelo conflito que ficou conhecido como Contestado. As autoridades não garantiam mais a segurança daquela área quanto a uma possível invasão. A Escola passou a funcionar em uma chácara situada no bairro Portão, e a conclusão daquele ano letivo se deu em dezembro (ANDRADE, 2002).

No início da década de 20, Dario cada vez mais se fechava no INP com seus amigos e familiares, e foi deixando aos poucos os embates públicos, como as disputas anticlericais. Já não escrevia com tanta assiduidade em revistas e jornais como fizera no início do século XX, e seus textos voltaram-se mais para a divulgação das ideias pitagóricas. No ano de 1923, torna-se diretor da Coluna Dórica, no jornal Gazeta do Povo (BEGA, 2001). Nesta coluna, além de textos de sua autoria, também eram publicados textos de membros do INP. Continuava escrevendo seus livros doutrinários, ainda com a esperança de que seus escritos alcançassem os corações e as almas dos leitores, porém, seus esforços já não reverberavam com a mesma força que outrora. No ano de 1932, aposenta-se do magistério e, no ano seguinte, publica a obra Atlântida. Esta obra possui um balanço de suas lutas e de seus sonhos. Em 1936, publica sua última obra: Jesus Pitagórico, um diálogo entre as figuras de Jesus e de Vellozo, no qual o próprio autor recebe alguns ensinamentos.

Percebemos que Vellozo foi um dos principais nomes de diversos movimentos intelectuais que se originaram em Curitiba e tiveram repercussões em nível nacional, além de ter exercido um grande papel no cenário da imprensa paranaense. Nesse sentido, Vellozo tentou de diversas maneiras interagir em seu contexto social, procurando colocar diversas de suas ideias em prática. 
A questão do conhecimento histórico era muito importante para Dario Vellozo. Logo, para Vellozo, a história estava longe de ser um conhecimento apenas para fins eruditos, mas possuía uma função prática e muito importante para toda a lógica do pensamento velloziano.

Assim, devemos primeiramente esclarecer algumas questões a respeito da relação de Vellozo com a história. Vellozo lançou mão do conhecimento histórico em diversos momentos de sua vida. Isso fez com que a história ganhasse um papel de destaque em seus textos, pois esse conhecimento oferecia a Vellozo grandes possibilidades, tornando-se uma peça-chave em algumas de suas estratégias de intervenção social.

Em seus discursos anticlericais, Vellozo utilizou a história enquanto um mecanismo para legitimar suas ideias contra o Clero. Neste sentido, para ele, mostrar alguns aspectos da história da Igreja Católica poderia prejudicar o prestígio dessa instituição, bem como diminuir sua influência na sociedade paranaense do período. Porém, não foi apenas ao embate anticlerical que Vellozo escreveu textos de conhecimento histórico. Além de seu livro Lições de História, ele escreveu cerca de quatorze textos que trabalham temas históricos.

Nesses textos, percebemos que a história possuía uma função social para Vellozo, ou seja, ensinar o presente sobre os erros e acertos do passado para que não ocorressem os mesmos enganos no futuro, além de buscar um passado glorioso que pudesse unir a população em torno da ideia de pátria.

Essa ideia de conceber a história enquanto uma forma de "guia" de erros e acertos foi formulada pelo romano Marco Túlio Cícero, na Antiguidade Clássica. Para essa concepção, o saber histórico era baseado na realização de um paralelismo com fatos do passado. Assim, essa área de conhecimento adquiria o sentido de "lição" ou "ensinamento" para as gerações do presente e do futuro, podendo adequar-se aos mais variados fins políticos ou sociais. Cícero defendia que o conhecimento histórico possuía o papel de educar os homens nas atividades político-intelectuais e indicar, por meio das experiências do passado, condutas que deveriam ser copiadas ou evitadas pela sociedade. Portanto, 
a história seria um cadinho contendo múltiplas experiências alheias, das quais nos apropriaríamos com um objetivo pedagógico; ou, nas palavras dos antigos, a história deixa-nos livres para repetir sucesso do passado, em vez de incorrer, no presente, nos erros antigos (KOSELLECK, 2006, p. 42).

Assim, Vellozo, em seu texto intitulado Da Instrução Pública publicado em 1904 e escrito a partir de uma fala sua durante a entrega de diplomas a uma turma de formandos da Escola Normal -, afirma que:

\begin{abstract}
A história universal vos disse a evolução da humanidade através dos séculos, seus conflitos e decepções, suas vitórias, suas conquistas, seu enlace magnético para um ponto invisível no espaço e no tempo, o fluxo e refluxo das vagas humanas impelidas para o futuro, para o desconhecido (VELLOZO, 1969b, p. 241).
\end{abstract}

Nesta passagem, podemos perceber que, para Vellozo, o conhecimento histórico ensina sobre o passado para tentar fazer mudanças no futuro, tornando-se uma maneira de pensar sobre o que pode ser repetido e o que precisa ser evitado no presente e no futuro. Contudo, para entendermos melhor esse pensamento velloziano, devemos olhar mais a fundo a noção criada por Cícero, a chamada historia magistra vitae.

Embora tenha surgido no pensamento greco-romano, o sentido de historia magistra vitae alcançou efetivamente sua propagação “[...] sob o cristianismo em correspondência com a imagem da vida de criaturas engendradas por um Deus onipotente e presente" (LIMA, 2006, p. 120). Assim, um acontecimento deflagrado em um determinado contexto histórico poderia ocasionar associações por parte de estudiosos que acreditavam ser possível a utilização desses eventos como formas de "lições" para as gerações do presente e do futuro (KOSELLECK, 2006).

Dessa forma, o recurso aos "exemplos" do passado, presente nas narrativas históricas dos gregos e romanos, claramente adaptava-se aos interesses pessoais, institucionais e valores sociais em diversos contextos 
históricos, pois

essa história pretendeu ser também memória. Coube-lhe então, durante séculos, lembrar e ensinar pelos exemplos reais e ilustres de que era a única depositária. Esta história magistra vitae pôde então servir com equanimidade aos políticos, filósofos, juristas e pedagogos (FALCON, 1997, p. 63, grifos do autor).

No contexto da chamada Idade Moderna, marcada no cenário europeu por diversas transformações políticas e culturais, as narrativas históricas passaram a possuir interesses distintos dos vislumbrados nas épocas anteriores, atendendo, muitas vezes, aos anseios das monarquias nacionais em processo de formação. Mas, mesmo com essas características e autonomia:

a história humanista e renascentista assume uma atitude dupla e contraditória perante a história. Por um lado, o sentido das diferenças e do passado, da relatividade das civilizações, mas também da procura do homem, de um humanismo e de uma ética em que a história, paradoxalmente, se torna magistra vitae, negando-se a si própria, fornecendo exemplos e lições atemporalmente válidos (LE GOFF, 2003, p. 68).

Assim, o papel de vários estudiosos renascentistas consistiu em analisar diversos aspectos da vida política e propor algumas "lições" e "conselhos" aos governantes (BOURDÉ; MARTIN, 1983). Logo na primeira metade do século XVIII, as bases da historia magistra vitae começaram a enfraquecer, pois a percepção de história como "ensinamento" que visava "esclarecer o homem político” (HARTOG, 1998) não correspondia aos anseios dos novos tempos revolucionários, perdendo seu sentido verdadeiro, pois não parecia adequar-se em um contexto no qual a história ganhava cada vez mais autonomia.

Apesar das inúmeras transformações políticas e sociais e, concomitantemente, na forma de conceber a história, muitos estudiosos ainda continuaram empregando em seus trabalhos as bases da história de Cícero. 
Assim, se a "velha história política no gênero magistra vitae experimentou algumas rudes desventuras no Século das Luzes, contudo, ela não estava completamente morta” (LOPES, 1997, p. 42). O próprio Voltaire, ao qual Vellozo nutria profundas admirações, afirmou que escreveria uma história da vida de Carlos XII para ensinar aos príncipes o que é preciso evitar (LOPES, 2001). Nessa percepção, a história era reconhecida em seu "valor de formação para os príncipes primeiramente, mas também para os súditos, contá-la é lícito, aprendê-la é útil” (HARTOG, 1998, p. 198).

No cenário historiográfico brasileiro, o topos da historia magistra vitae também se fizeram presentes, principalmente entre os membros do Instituto Histórico e Geográfico Brasileiro (IHGB), que viam com bons olhos essa forma de entender a história, como "lições" do passado.

O IHGB foi criado em 1838, no Rio de Janeiro, e surgiu com o objetivo de construir uma história e uma identidade brasileira. Como afirma Lilia Schwarcz:

o estabelecimento carioca cumpria o papel que lhe foi reservado [...] construir uma história da nação, recriar um passado, solidificar mitos de fundação, ordenar fatos buscando homogeneidade em personagens e eventos até então dispersos (SCHWARCZ, 2000, p. 99).

Logo, essa instituição tornou-se o principal centro de intelectuais no século XIX, como aponta Reis:

o IHGB será o lugar privilegiado da produção histórica durante o século XIX, lugar que condicionará as reconstruções históricas, as interpretações, as visões do Brasil e da questão nacional (REIS, 2005, p. 26).

A primeira atuação do Instituto no campo historiográfico diz respeito ao projeto que lhe deu início, que consistia na coleta de toda a documentação 
referente ao império e no armazenamento desses documentos no Instituto. Segundo Schwarcz, “[...] os institutos se proporão a cumprir uma tarefa monumental: 'Colligir, methodizar e guardar' (RIHGB, 1839/I) documentos, fatos e nomes para finalmente compor uma história nacional [...]" (SCHWARCZ, 2000, p. 99). Após essa etapa inicial, o IHGB procurou enfatizar publicações referentes à História do Brasil. Nesse momento, foi realizado um concurso acadêmico, em 1840, promovido pelo Instituto, que tinha como pretensão, segundo Temístocles Cezar:

[...] oferecer um prêmio àquele que apresentasse o melhor plano para se escrever a "história antiga e moderna do Brasil". Especificamente, esse projeto teria que contemplar a organização de diferentes perspectivas historiográficas, tais como a história política, civil, eclesiástica e literária (CEZAR, 2004, p. 174).

O vencedor desse concurso foi o bávaro Carl Friedrich Phillip von Martius, com a dissertação intitulada Como se deve escrever a história do Brasil. Porém, ele recusou a tarefa proposta pelo Instituto de escrever uma história brasileira. Esse trabalho ficou a cargo do brasileiro Francisco Adolfo de Varnhagen, que publicou a obra História geral do Brasil a partir de 1854, trabalho cuja prioridade era legitimar uma história dos colonizadores, enaltecendo a figura do português como o povo civilizado que trouxe o progresso ao Brasil.

O Instituto buscava constituir uma "história oficial” para a jovem nação, pautada em exemplos "edificantes" de alguns heróis, principalmente portugueses, ou nos paralelismos entre acontecimentos do passado e do presente. Nesse sentido, os escritores do IHGB visavam instaurar os parâmetros de uma narrativa do passado nacional, monarquista e católico, no qual os eventos históricos eram apresentados por meio da perspectiva de "lição".

Lições "patrióticas" e destinadas a "eternizar" o passado imperial brasileiro eram ideias correntes que a alta hierarquia dirigente do IHGB 
almejava difundir no meio intelectual do período, estabelecendo os pilares que iriam nortear a historiografia nacional do século XIX. Assim, aquele pequeno “cenáculo dos pensadores da época sob a égide do imperador” (SODRÉ, 2002, p. 267) possuía em comum a ideia de elaborar a história política do país, seguindo, em alguns momentos, a "luz" do pensador romano Cícero (CEZAR, 2004).

Nessa perspectiva, vários pensadores nacionais do período, direta ou indiretamente ligados ao IHGB, também almejavam inserir em seus estudos estes valores, propiciando à historiografia nacional, na era imperial, um discurso histórico sobre o jovem país, em que se repetiam "lições" relacionadas ao passado. Nesse sentido, era bastante natural a existência de referências diretas ao orador e político Cícero, pois “a historia magistra vitae não é apenas um adágio erudito, ela é também um princípio organizador que justifica e ao mesmo tempo orienta as investigações do IHGB” (CEZAR, 2004, p. 14).

Em uma nação que se encontrava em pleno processo de formação institucional, política e ideológica, como era o Brasil à época, a produção de narrativas históricas adquiriu um valor fundamental, pois servia tanto às pretensões intelectuais como às políticas de uma reduzida elite letrada. Por isso, diversos membros da intelectualidade no período preocupavam-se em consolidar as bases de uma história oficial, voltada para a construção do "passado nacional”, cujo objetivo mais eminente caracterizava-se pela perspectiva de elaboração das "histórias regionais que garantam uma direção à centralização” (REIS, 2005, p. 27), compondo a unidade político-territorial do país.

A preocupação em consolidar a união do território nacional fez com que o Império e o IHGB incentivassem a criação de institutos regionais. Segundo Guimarães: 
dever-se-ia, em última instância, concentrar a soma de conhecimento acumulados sobre o Brasil (GUIMARÃES, 1988, p. 16).

Apesar dessa ideia de criação de institutos regionais ter surgido em meados do século XIX, esses institutos demoraram a se estruturar. Assim, podemos mencionar, por exemplo, o Instituto Archeologico e Geographico Pernambucano, fundado no ano de 1862, o Instituto Historico e Geographico de São Paulo e o Instituto Geographico e Historico da Bahia, ambos criados em 1894, e o Instituto Histórico e Geográfico Paranaense (IHGPR), fundado em 1900. Este Instituto foi fundado nos albores da República, fruto de um esforço de alguns jovens letrados paranaenses, com o objetivo de pesquisar e divulgar a história do Paraná.

O Instituto Histórico e Geográfico Paranaense foi fundado no dia 24 de maio de 1900, em meio às comemorações do quarto centenário do "descobrimento do Brasil", promovidas pelo Estado do Paraná. Tinha como principal finalidade, de acordo com seu estatuto de fundação, "Coligir, estudar, publicar e arquivar os documentos que sirvam à historiografia do Paraná, promovendo a difusão de seu conhecimento pela imprensa e pela tribuna" (BIHGP, 1917, p. 22). Essa passagem do estatuto da instituição paranaense assemelha-se bastante ao estatuto do IHGB já citado acima, mostrando que o IHGB era o modelo a ser seguido pelos institutos regionais.

Os fundadores do Instituto eram pessoas que já possuíam algum prestígio no cenário intelectual paranaense. O principal idealizador do IHGPR foi Romário Martins, que organizou as reuniões e convidou os demais membros. Apesar de 16 nomes terem sido convidados, apenas seis puderam atender ao pedido inicial de Romário Martins e compareceram no dia da reunião de criação do instituto (BELTRAMI, 2002). Esses membros estavam de alguma maneira em sintonia em determinados aspectos ideológicos, quer seja por meio da poesia simbolista, das ideias anticlericais, quer seja, ainda, devido à maçonaria. Assim, os nomes convidados por Martins foram Dario Vellozo, Emiliano Pernetta, Julio Pernetta, Nestor Pereira de Castro, Camilo Vanzolini, Jocelim Morocines Borba, 
Ermelino Agostinho de Leão, José Bernardino Bormann, Luiz Tonise, Manoel Francisco Ferreira Correia, Sebastião Paraná de Sá SottoMaior, Bento Fernandes de Barros, Cândido Ferreira de Abreu, José Cândido da Silva Muricy e Lúcio Leocádio Pereira (Ibidem).

Aqui, percebemos outra relação de Vellozo com a história. Seu nome consta como um dos primeiros lembrados por Romário Martins, além de Dario ter sido orador e depois secretário do IHGPR. Destacamos ainda que as primeiras reuniões dos membros ocorreram nas salas do Club Curitibano, que, no ano de fundação do IHGPR, era presidido por Ciro Vellozo. O presidente auxiliou de maneira indireta na criação do Instituto, abrindo as portas do clube para as reuniões e facilitando os encontros dos fundadores.

Apesar de todo o esforço para a criação do IHGPR, o Instituto teve pouca representatividade no cenário paranaense, na primeira década do século $\mathrm{XX}$, devido à falta de estrutura. Isso pode ter ocorrido por fatores como a falta de sede própria, que dificultava as reuniões, e a pouca participação dos membros, já que muitos não compareciam aos encontros. O Instituto começou a ganhar mais visibilidade com o início da publicação de seus manuais, que ocorreu apenas em 1917.

\section{A DESCOBERTA DE UM GRANDE INTELECTUAL...}

Na década de 1920, o IHGPR começou a ganhar mais destaque no cenário cultural paranaense com o projeto de uma historiografia "Paranista", idealizado por Romário Martins. Nesse momento, um grupo, reunido em torno desse personagem, tentou forjar uma identidade paranaense. Assim, o IHGPR passou a ser a principal instituição de disseminação das ideias Paranistas, publicando diversos textos sobre essa questão e promovendo encontros para discutir essas ideias. 
Porém, a participação na criação do IHGPR não foi a única atividade elaborada por Vellozo para comemorar o IV centenário do descobrimento do Brasil. Vellozo organizou uma edição especial da revista Club Coritibano para homenagear essa data. A revista teve como objetivo fazer um breve balanço sobre a história do Paraná, além de uma projeção sobre as possibilidades de contribuição que o Estado poderia oferecer à nação (BELTRAMI, 2002). Foram convidados por Dario Vellozo, ao todo, 16 escritores; desses participantes, dez atuaram com ele na fundação do IHGPR. Os artigos abordam diversos períodos históricos do Paraná e do Brasil, de histórias específicas, como imprensa, literatura e belas artes.

O artigo de Vellozo abre a edição da revista e chama-se Descobrimentos Marítimos. O Brasil. Neste texto, Vellozo discorre sobre a jornada portuguesa até a chegada no Brasil, elogiando a bravura desse povo em aventurar-se para alcançar outras localidades, além de comentar um pouco sobre algumas revoltas populares. Ele termina o artigo falando sobre a República e sobre um novo tempo que começou com esse regime político.

Apesar de ser um texto relativamente curto, mostra-nos algumas características importantes das obras de Vellozo, como na seguinte passagem:

\footnotetext{
Nesse rememorar das idades mortas vai, de envolta com muita mágoa e muita tristeza, a homenagem dignificante pelos que se foram, entre tábuas de esquifes, para o tálamo feral da sepultura. Desse rememorar das idades mortas, ressalta, numa eloqüente lição inolvidável, a lide afanosa das gerações passadas pelas gerações futuras. É o legado honesto de pais a filhos, é um exemplo edificante da perseverança e do trabalho (VELLOZO, 1969b, p. 212-213).
}

Nesse excerto, podemos perceber que, para Vellozo, o estudo do passado pode trazer contribuições ao futuro, reiterando toda a discussão que já fizemos sobre a historia magistra vitae. Nesse sentido, a história pode ser interpretada como um conhecimento capaz de servir de exemplo para a sociedade, bem como de modelo para as atuações da população. Vellozo utiliza 
muito essa questão, em um duplo sentido, haja vista que ele enaltece alguns personagens históricos e os utiliza como modelos de cidadãos.

Em uma conferência proferida em 29 de julho de 1904, a convite da Associação Cívica Floriano Peixoto, Vellozo procurou enaltecer de várias maneiras a figura do Marechal Peixoto. O autor descreve Peixoto como sendo um dos principais responsáveis pela instauração do novo regime político. Segundo Vellozo, foi o Marechal que conseguiu amparar "[...] o oscilante edifício da República, o braço forte afasta as pretensões do altar e do trono, os lábios enérgicos respondem fulminantemente à arrogância estrangeira" (VELLOZO, 1969b, 234). E termina afirmando que "o Marechal fica em nossos fastos como lição e exemplo" (VELLOZO, 1969b, p. 352).

Vale lembrar que o final do século XIX e início do século XX foram marcados, no Brasil, pela transição do regime político. Diversos intelectuais defenderam suas respectivas causas em diversos momentos e Vellozo insere-se no grupo dos defensores do regime republicano. Podemos concluir que a intenção de Vellozo era de construir uma imagem positiva do líder republicano para servir de exemplo à população.

\section{AS OBSERVAÇÕES FINAIS...}

Percebemos também a preocupação de Velloso em deixar a figura do Marechal como um exemplo cívico, um modelo a ser seguido, mostrando um homem que lutou pela República e possuiu uma índole "pura”. Assim, notamos as ideias de "lição", no sentido proposto pela historia magistra vitae, e ensinamento ao povo do que foi feito por esse personagem, e que pode, também, ser repetido pela população. Percebe-se, ainda, a preocupação em enaltecer um personagem histórico para servir de exemplo e de legitimação de alguns ideais.

Devido ao ecletismo teórico presente no pensamento de Dario Vellozo, é difícil percebermos todos os diálogos que ele travou com diversas correntes de 
pensamento. Porém, conseguimos perceber sua relação com a perspectiva da historia magistra vitae. Nesse sentido, para Vellozo, a história possuiria a função de estudar o passado para ensinar o presente e o futuro a respeito dos erros e acertos das civilizações passadas. Isso faz com que a história seja um mecanismo de intervenção social, haja vista que Vellozo utiliza da história para legitimar algumas de suas ideias, bem como para defender alguns de seus pontos de vista. Essa questão fica clara quando Vellozo utiliza a figura de Marechal como um "exemplo" para legitimar o sistema republicano que ele defendeu ferrenhamente por toda sua vida.

Logo, o topos da historia magistra vitae surge com grande força no pensamento de Dario Vellozo. Em um cenário de grandes mudanças políticas e sociais, Vellozo lançou mão de uma estratégia havia muito tempo consagrada para tentar salientar e legitimar alguns de seus argumentos. Assim, Vellozo escolhia determinados acontecimentos históricos para defender algumas de suas concepções. Nesse sentido, a história era mobilizada como uma importante estratégia de intervenção social por Vellozo.

\section{REFERÊNCIAS}

ANDRADE, Maria Lucia. Educação, cultura e modernidade: o projeto formativo de Dario Vellozo. 2002. Dissertação (Mestrado em Educação) Programa de Pós Graduação em Educação, Universidade Federal do Paraná, Curitiba, 2002.

BEGA, Maria Tarcisa Silva. Sonho e invenção no Paraná: geração simbolista e a construção de identidade regional. 2001. Tese (Doutorado em Sociologia) - Programa de Pós Graduação em Ciências Sociais, Universidade de São Paulo, São Paulo, 2001.

BELTRAMI, Rafael Caminha de Carvalho. Da poesia na ciência: fundadores do Instituto Histórico e Geográfico do Paraná, uma história de suas ideias (1900). 2002. Dissertação (Mestrado em História) - Programa de Pós Graduação em História, Universidade Federal do Paraná, Curitiba, 2002. 
BOURDÉ, Guy; MARTIN, Hervé. As escolas históricas. Portugal: Ed. MiraSintra, 1983.

CAMPOS, Nevio de. Laicato católico: o papel dos intelectuais no processo de organização do projeto formativo da Igreja Católica no Paraná (1926-1938). 2002. Dissertação (Mestrado em Educação) - Programa de Pós Graduação em Educação, Universidade Federal do Paraná, Curitiba, 2002.

CEZAR, Temístocles. Como deveria ser escrita a história do Brasil no século XIX. Ensaio de história intelectual. In: PESAVENTO, Sandra (Org.). História cultural: experiências de pesquisa. Porto Alegre: Editora da UFRGS, 2004, p. 173-208.

CORREA, Amélia Siegel. Imprensa e política no Paraná: prosopografia dos redatores e pensamento republicano no final do século XIX. 2006. Dissertação (Mestrado em Sociologia) - Programa de Pós Graduação em Ciências Sociais, Universidade Federal do Paraná, Curitiba, 2006.

D'ONOFRIO, Salvatore. Literatura ocidental. Autores e obras fundamentais. 2. ed. São Paulo: Ática, 2002.

FALCON, Francisco. História e poder. In: CARDOSO, Ciro Flamarion; VAINFAS, Ronaldo (Org.). Domínios da história: ensaios de teoria e metodologia. Rio de Janeiro: Elsevier, 1997.

GUIMARÃES, Manoel Salgado. Nação e Civilização nos trópicos: o Instituto Histórico e Geográfico Brasileiro e o projeto de uma História Nacional. Estudos Históricos, Rio de Janeiro, v. 01, p. 5-27, 1988.

HARTOG, François. A arte da narrativa histórica. In: BOUTIER, Jean; JULIA, Dominique (Org.). Passados Recompostos: campos e canteiros da História. Rio de Janeiro: Editoras UFRJ/FGV, 1998.

NETTO, Silveira. O cenário. Revista do Club Coritibano. ano V, n. 18, Curitiba: Typographia paranaense, 1894 .

IMPRENSA PARANAENSE. Boletim do Instituto História e Geográfico Paranaense. Curitiba, 1917.

KOSELLECK, Reinhart. Futuro passado: contribuição à semântica dos tempos históricos. Trad. Wilma Patrícia Maas e Carlos Almeida Pereira. Rio de Janeiro: Contraponto, Ed. PUC-Rio, 2006.

LE GOFF, Jacques. História e memória. 5. ed. Campinas, SP: Editora da Unicamp, 2003. 
LIMA, Luiz Costa. História, ficção, literatura. São Paulo: Companhia das Letras, 2006.

LOPES, Marcos Antônio. O político na modernidade. São Paulo: Edições Loyola, 1997.

LOPES, Marcos Antônio. Historiador: uma introdução ao pensamento na época do Iluminismo. Campinas: Papirus, 2001.

MARCHETTE, Tatiana Dantas. Corvo no galho das acácias: o movimento anticlerical em Curitiba (1896-1912). Curitiba: Aos Quatro Ventos, 1999.

MARTINS, Alfredo Romário. História do Paraná. Curitiba: Farol do Saber, 1995 .

MURICY, Andrade. Panorama do movimento simbolista brasileiro. 2. ed. Brasília: Conselho Federal de Cultura: INL, 1973. 2v.

NEGRÃO, Francisco de. Genealogia Paranaense. Curitiba: Impressora Paranaense, 1929. v. 3.

PEREIRA, Luis Fernando Lopes. Paranismo: o Paraná inventado; cultura e imaginário no Paraná da I República. 2. ed. Curitiba: Aos Quatro Ventos, 1998.

PILOTTO, Erasmo. Dario Vellozo: cronologia. Curitiba: s.ed, 1969.

REIS, José Carlos. As identidades do Brasil: de Varnhagen a FHC. 7. ed. Rio de Janeiro: Editora FGV, 2005.

SILVEIRA, Tasso da. Dario Vellozo: perfil espiritual. 1921.

SCHWARCZ, Lilia Moritz. O espetáculo das raças: cientistas, instituições e questão racial no Brasil (1870-1930). São Paulo: Companhia das Letras, 2000.

SODRÉ, Nelson Werneck. História da literatura brasileira. 10. ed. Rio de Janeiro: Graphia, 2002.

SOUZA, Fabrício Leal de. Nação e herói: a trajetória dos intelectuais paranistas. 2002. Dissertação (Mestrado em História) - Programa de Pós Graduação em Educação, Faculdade de Ciências e Letras, Unesp/Assis, 2002.

VELLOZO, Dario. Obras I. Curitiba: Instituto Neo-Pitagórico, 1969a. 1 v.

VELLOZO, Dario. Obras II. Curitiba: Instituto Neo-Pitagórico, 1969b. 2 v.

VELLOZO, Dario. Obras III. Curitiba: Instituto Neo-Pitagórico, 1969c. 3 v.

VELLOZO, Dario. Obras IV. Curitiba: Instituto Neo-Pitagórico, 1975. 4 v. 


\section{VALENTE, Silza Maria Pazello. A presença rebelde na Cidade Sorriso:} contribuição ao estudo anarquista em Curitiba (1890-1920). 1992. Dissertação (Mestrado em Educação) - Programa de Pós Graduação em Educação, Universidade Estadual de Campinas (Unicamp), Campinas, 1992.

VIEIRA, Carlos Eduardo. Jornal Diário como fonte e como tema para a pesquisa em História da Educação: um estudo da relação entre imprensa, intelectuais e modernidade nos anos de 1920. In: OLIVEIRA, Marcus Aurélio Taborda de. (Org.). Cinco estudos sobre a História da Educação. Belo Horizonte: Autêntica, 2007.

TRINDADE, Etelvina Maria de Castro; ANDREAZZA, Maria Luiza. Cultura e educação no Paraná. Curitiba: SEED, 2001.

ERNANDO BRITO GONÇALVES JUNIOR é pós-doutorando em História pela Universidade Estadual do Centro-oeste, doutor em História pela Universidade Federal do Paraná, com Estágio de Doutorado Sanduíche na Cidade do México, sob orientação do doutor Bernd Hausberger, Colégio de México, com financiamento da CAPES. Atualmente é professor do departamento de Pedagogia da Universidade Estadual do Centro-oeste. Desenvolve pesquisas sobre História da América, Revolução Mexicana, Cinema latino-americano, História e Cinema, História dos Estados Unidos, História da Educação, Ensino de História e Educação e Cinema.

E-mail: ernandobrito@gmail.com

(1) http://orcid.org/0000-0002-9456-1938

VANESSA ELISABETE RAUE RODRIGUES é pós-doutoranda em Educação e doutora em Educação na Universidade Estadual de Ponta Grossa. É pesquisadora do Grupo GEPÊPrivação da Universidade de São Paulo e participa dos Grupos História, Sociedade e Educação no Brasil e da Universidade do Centro-Oeste. É Coordenadora Pedagógica do Centro de Educação Básica para Jovens e Adultos, Nova Visão instalada no Complexo Penitenciário de Guarapuava/PR e atua como Docente Colaboradora da Universidade Estadual do Centro Oeste, Unicentro no Departamento de Pedagogia.

E-mail: vanessarauerodrigues@gmail.com

(b) http://orcid.org/0000-0003-4943-921X 
Revista História da Educação (Online), 2020, v. 24: e95350

Recebido em: 07 de agosto de 2019

Aprovado em: 29 de outubro de 2019

(c) (i)

Revista História da Educação - RHE

Associação Sul-Rio-Grandense de Pesquisadores em História da Educação - Asphe

Artigo de acesso aberto distribuído nos termos de licença Creative Commons. 